Spring 4-1-2013

\title{
Research On Smart Shopper Feelings: An Extension
}

Pelin Bicen

Penn State University - Erie, pxb40@psu.edu

Sreedhar Madhavaram

Cleveland State University, s.madhavaram@csuohio.edu

Follow this and additional works at: https://engagedscholarship.csuohio.edu/bus_facpub

Part of the Marketing Commons

How does access to this work benefit you? Let us know!

\section{Publisher's Statement}

This is an Author's Accepted Manuscript of an article published in Journal of Marketing \& Theory Practice 04-01-2013, available online: http://www.tandfonline.com/10.2753/ MTP1069-6679210207.

\section{Original Published Citation}

Bicen, P. \& Madhavaram, S. (2013). Research on smart shopper feelings: An extension. Journal of Marketing Theory and Practice, 21(2), 221-234. doi: 10.2753/MTP1069-6679210207

This Article is brought to you for free and open access by the Monte Ahuja College of Business at EngagedScholarship@CSU. It has been accepted for inclusion in Business Faculty Publications by an authorized administrator of EngagedScholarship@CSU. For more information, please contact library.es@csuohio.edu. 


\title{
Research Note
}

\section{RESEARCH ON SMART SHOPPER FEELINGS: AN EXTENSION}

\author{
Pelin Bicen and Sreedhar Madhavaram
}

\begin{abstract}
Drawing from Weiner's (1985) attributional theory, this study extends the research on smart shopper feelings by testing (1) the relationships involving all causal dimensions of attributions and (2) affective consequences as mediating the relationships between causal dimensions of attributions and behavioral consequences. The results reveal that consumers feel happier when they attribute a price discount's cause to an unstable reason and feel more appreciative if they think that sellers have control over discounts, and happiness completely mediates the relationship between internal locus and consumers' behavioral responses. This research has specific theoretical and practical implications in the context of smart shopper feelings.
\end{abstract}

Sales promotions have increased in popularity over the past few decades. According to the "2009 Promo Industry Trends Report" (2009), price discounts count among the top sales promotion practices and they have increased many companies' top-line performance to a considerable extent.

Reflecting the importance of price promotions for firms, there is burgeoning research that addresses the effect of price promotions on brand evaluations (e.g., DelVecchio, Henard, and Freling 2006), repeat purchase (e.g., Ailawadi, Lehmann, and Neslin 2001), brand loyalty (e.g., Balachander, Ghosh, and Axel 2010), variety seeking (e.g., Lin and Lin 2009), and purchase amount (e.g., Manning and Sprott 2007). The central premise of these research studies is that price discounts have an effect on consumers who are concerned with only the economic value of the money saved. However, research and business practices show us that this is not always the case (e.g., Ailawadi, Lehmann, and Neslin 2001; Chandon, Wansink, and Laurent 2000; Schindler 1998). This leads to an important question: Are there benefits other than monetary savings that motivate consumers to consider price discounts? Schindler's (1998) research examines the nonmonetary motivational effect of price discounts on consumer behavior, and provides preliminary evidence to

Pelin Bicen (Ph.D., Texas Tech University), Assistant Professor of Marketing, Black School of Business, Penn State University-Erie, Erie, PA, pxb40@psu.edu.

Sreedhar Madhavaram (Ph.D., Texas Tech University), Associate Professor of Marketing, Monte Ahuja College of Business, Cleveland State University, Cleveland, OH, s.madhavaram@csuohio .edu. smart shopper feeling. Our research aims to systematically extend Schindler's work on smart shopper feelings and contribute to the behavioral pricing literature by (1) showing that a smart shopper feeling is not a one-of-a-kind event; (2) examining new, theoretically grounded relationships regarding retailers' price discount strategies; and (3) testing a structural model with multiple relationships among causal attributions, affections, and behaviors. This study is the first known extension of Schindler's (1998) research on smart shopper feelings (see Table 1) and provides practical implications to retailers in designing and executing price discount activities.

\section{ATTRIBUTIONAL THEORY PERSPECTIVE}

For Schindler (1998), based on attributional theory, consumers who perceive themselves as responsible for obtaining a discount show positive feelings of getting the discount and have a high likelihood of repeat purchase and wordof-mouth (WOM) communication. Contra the attribution approach, attributional theory mainly focuses on understanding the effects of causal attributions on affects and behaviors rather than the causes themselves.

According to attributional theory, when faced with an attribution-eliciting event (e.g., price discount), a person classifies the event's cause along several dimensions: causal locus (where cause is internal or external to the person),

The authors are thankful to Tillmann Wagner and Naveen Gudigantala for their help on this project. 
Table 1

Replication and Extension Hypotheses

\begin{tabular}{lll}
\hline Hypotheses & \multicolumn{1}{c}{ Status } & \multicolumn{1}{c}{ Results } \\
\hline $\mathrm{H} 1$ & Replication & Confirmed \\
$\mathrm{H} 2$ & Extension & Confirmed \\
$\mathrm{H} 3$ & Extension & Partial support \\
$\mathrm{H} 4$ & Extension & Confirmed \\
$\mathrm{H} 5$ & Extension & Confirmed \\
$\mathrm{H} 6$ & Extension & Rejected \\
$\mathrm{H} 7$ & Extension & Partial support \\
\hline
\end{tabular}

stability (whether the cause is short lived or long lasting), and controllability (whether the cause is subject to volitional control). The causal ascriptions play a key role in the emotion process, and each causal dimension is uniquely related to a set of feelings. Finally, emotional reactions play a central role in motivated behavior (Weiner 1985). Specifically, instead of evaluating incentive values in terms of the objective properties of the goal (e.g., 25 percent price discount), attributional theory considers incentive to mean the consequences of the subjective value of the goal. Although causal attributions do not influence the objective properties of the goal, they guide the emotional reactions/subjective consequences of goal attainment (e.g., a discount earned by hard work might increase consumer self-confidence; a discount received by the retailer's volition is likely to beget gratitude).

Schindler (1998) focuses on mainly one causal dimension-locus of causality. He combines the other two dimensions into a single aspect as stable controllability, considering them closely related in the context of perceived responsibility for obtaining a price discount. Briefly, Schindler states that if a consumer perceives internal causal factors to be under control and stable over time, then perceived responsibility for obtaining a price discount is likely to be greater. The current study extends Schindler's work by taking the focal point from the consumer per se (e.g., stable controllability of the consumer getting the price discount) and extending it to the causal attributions of price discount activities in general (e.g., stability, controllability, and locus aspect of price discounts). Accordingly, the current study focuses on firms' price discount activities and aims to provide firms with more practical implications regarding how consumers process price discount activities and how this process influences their behavior. Therefore, the current study treats the stability and controllability dimensions separately and relates them to price discounts' causes.
The attributional framework assumes a sequence in which cognitions enter into the emotion process to further refine and differentiate an experience. Briefly, depending on the chosen causal attribution, a different set of emotions (psychological consequences) is generated that eventually affects consumers' behavioral reactions (see Figure 1).

\section{Brief Discussion on Emotions}

In this study, by emotion, we mean a mental state of readiness that is triggered by cognitive appraisals of events that may result in specific actions to affirm or deal with the emotion, depending on its nature and meaning for the person experiencing it (Lazarus 1991). Although emotions, moods, and attitudes are all discussed as valenced feeling states, they have some subtle differences (Bagozzi, Gopinath, and Nyer 1999; Beedie, Terry, and Lane 2005). For instance, emotions differ from moods and attitudes in the way they arise. Emotions have a specific referent (e.g., self-caused, other caused, or circumstance caused), and they arise in response to the evaluative judgments an individual makes for something of relevance to his or her well-being (e.g., a consumer becomes pleased when he or she receives an instant price discount as a result of a retailer's rollback price activity; this way, the consumer can save money). In other words, emotions occur in response to changes in specific plans and goal-relevant events. Further, arousal is not necessarily a part of mood and attitude, which are elicited when the cognitive system is maintained in an emotion mode for a period (Oatley and Jenkins 1992; Smith et al. 1993). In addition, strength of felt subjective experience and magnitude of response are more direct and stronger in emotions than they are in moods and attitudes (Bagozzi, Gopinath, and Nyer 1999; Wierzbicka 1992).

Although there are many emotion types, we focus only on the ones that are relevant to the current study: happiness, self-confidence, and appreciation. We use Roseman's (1991) appraisal theory of emotion for our conceptualizations. The essence of the theory is that subtle combinations of appraisals lead to discrete emotional responses. For example, happiness, self-confidence, and appreciation differ in agency appraisal but have similar traits in motive consistency and appetitive appraisals. Happiness occurs when a person sees the circumstance as the source of the positive outcomes (e.g., circumstance caused), whereas selfconfidence is experienced as a consequence of attributing a positive outcome to the self (e.g., self-caused) (Bearden, Hardesty, and Rose 2001; Honea and Dahl 2005), and appreciation results if and only if the act of the benefactor 
Figure 1 Conceptual Framework of Causal Dimensions and Psychological and
Behavioral Consequences to Price Discounts

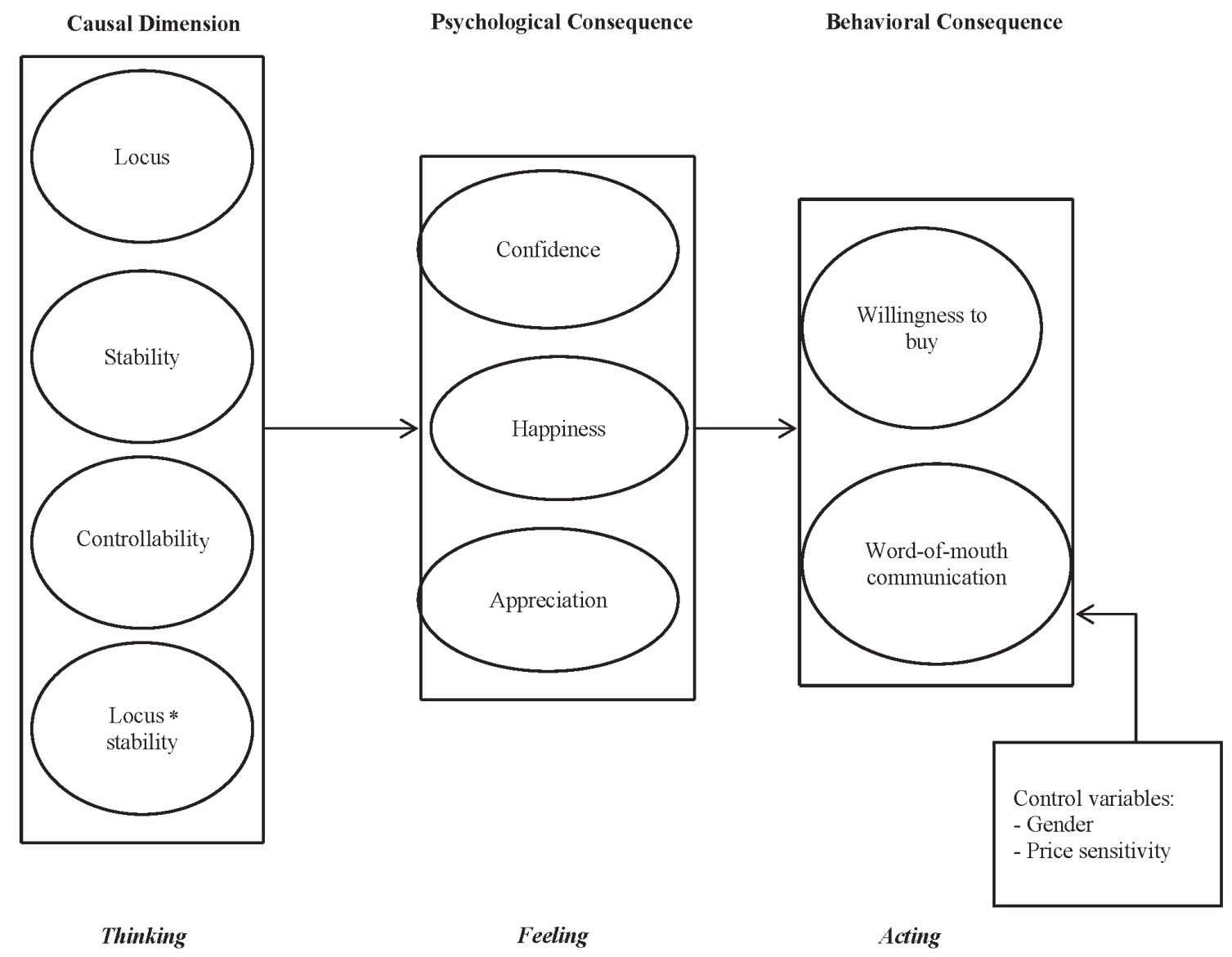

was under volitional control and was intended to benefit the recipient (e.g., other caused) (Adler and Fagley 2005; Weiner 1985). In other dimensions, all three emotions are motive consistent (e.g., goal relevant) and appetitive (e.g., rewarding).

\section{Locus of Causality}

The analysis of the structure of causality begins with the locus dimension (Weiner 1985). Furthermore, the cause can be located either in the consumer (internal locus) or in the seller (external locus). Internal locus of causality occurs when a consumer expects a specific outcome because the information needed to build that expectation makes the consumer responsible for that specific outcome (Wagner, Hennig-Thurau, and Rudolph 2009). Transferring this reasoning into the context of price discounts, this paper argues that consumers who are determined to get a discount will be involved in an elaborate and persistent price search.
This intensive price search builds certain expectations and makes them feel responsible when they find a price discount (Bearden, Hardesty, and Rose 2001).

As mentioned above, particular combinations of appraisals lead to discrete emotions (Lazarus 1991; Peine, Heitmann, and Herrmann 2009). Therefore, although happiness is a circumstance-caused emotion (agency appraisal), it is also triggered by goal relevance and motive consistency appraisals. Simply, there is more goal relevance in finding a price discount for consumers who are determined to find one than for consumers who find it by chance. It is merely more consistent with internally locused consumers' motives. Self-confidence is described as a positively valenced, self-focused emotion. Bearden, Hardesty, and Rose (2001) conceptualize self-confidence as a feeling, and define it as the extent to which an individual feels capable and assured with respect to his or her marketplace decisions and behaviors. Therefore, we argue that consumers who attribute price discounts to internal causes not only will 
have more self-confidence but will also be more pleased and happier than consumers who attribute a price discount to external reasons. This is consistent with Schindler's (1998) primary hypothesis:

Hypothesis 1: The more consumers attribute a price discount's cause to internal factors, the greater their levels of (a) self-confidence and (b) happiness.

\section{Stability of Causality}

The causes of price discounts may be relatively temporary (e.g., cleaning stock, rollback prices) or fairly permanent (e.g., everyday low price policy [EDLP]). In this study, based on the behavioral pricing literature and appraisal theory, we argue that when consumers learn that price is reduced temporarily, their affective reaction to the price discount will be more positive than when they learn that the price reduction is permanent.

According to the behavioral pricing literature, consumers treat consumption and shopping not only as a utilitarian activity but also as a hedonic experience (Chandon, Wansink, and Laurent 2000; Hirschman 1984; Holbrook et al. 1984). Briefly, utilitarian benefits are functional and cognitive and help consumers maximize the economy of their shopping (e.g., saving money), whereas hedonic benefits are experiential and affective and provide consumers with intrinsic stimulation, fun, and pleasure. While EDLP fits into the utilitarian dimension (e.g., Grewal et al. 1998), temporary price promotions fit into the value expression benefit, which entails both the utilitarian and hedonic dimensions (e.g., Chandon, Wansink, and Laurent 2000; Honea and Dahl 2005; Peine, Heitmann, and Herrmann 2009).

Appraisal theory maintains that appraisals play a central role in emotion formation (e.g., happiness) (Bagozzi, Gopinath, and Nyer 1999; Lazarus 1991). In the case of price promotions, it is not the temporary or permanent price reductions that produce emotions but, rather, the psychological appraisal made by the consumers evaluating and interpreting the promotion event. In this case, while consumers make an appraisal of increase in acquisition utility with permanent price reductions, their appraisal of the temporary price reduction includes an increase in both their acquisition utility (e.g., saving money) and hedonistic experience (e.g., fun/pleasure seeking) (Chandon, Wansink, and Laurent 2000; Gartner|G2 2004). Differences between these appraisals reflect on the formation of positive emotions (e.g., happiness) (Lazarus 1991). As noted before, happiness is formed with the particular combination of different appraisals: motive consistency, goal relevance, and appetitive (e.g., presence of a reward). In the temporary price reduction event, the price discount is motive consistent (e.g., saving money-utilitarian benefits are met) and appetitive (e.g., discount for a shorter period of time-need for value expression and hedonistic benefits are met). However, in the EDLP condition, happiness is formed only with motive consistency (e.g., economic benefits). Therefore, we argue that evaluating a temporary price reduction event has an ability to make consumers more pleased and happier than does evaluating an EDLP event. Further empirical support for our argument comes from Ailawadi, Lehmann, and Neslin (2001) and Garretson and Burton (2003). Both of those studies found that although consumers benefited from long-term discount initiatives, there was a strong negative reaction from many consumers regarding the conversion of a temporary price reduction to an EDLP.

Therefore, as an extension to Schindler's (1998) work, which did not hypothesize the effect of the stability of the cause of a price discount on consumers' affective responses, we propose:

\section{Hypothesis 2: The more consumers attribute a price}

discount's cause to an unstable reason, the greater their levels of happiness.

Building on our discussion of the locus and stability dimensions, we also hypothesize that when a consumer makes an internal attribution concerning the cause of a discount, in addition to attributing instability to that cause, this internal attribution should further increase the feeling of happiness and self-confidence. In other words, if a consumer is persistently looking for a price discount, that consumer's feeling of happiness should become stronger if he or she learns that the respective price discount is for a short period. This is consistent with Holbrook et al.'s (1984) playful consumption discussion. Consumers who look for price discounts are motivated to find deals. Their intrinsic motivation involves seeking and conquering challenges in a manner that produces a positive affect (e.g., happiness) associated with the feeling of efficacy and having done well (e.g., self-confidence) (Bagozzi, Gopinath, and Nyer 1999; Roseman 1991). Schindler (1998) proposes a similar hypothesis. However, in his case, the causal attribution is about the stable controllability of an internal reason. In the current case, it is the stability of a cause of a price discount. Since the two studies examine different questions, the following is considered an extension of Schindler's study: 
Hypothesis 3: When the reason for a price discount is seen as internal, the attribution that the cause of a price discount is also unstable will have a greater effect on (a) self-confidence and (b) happiness.

\section{Controllability of Causality}

The controllability component of attribution theory describes the degree to which the causes of price discounts are volitional and can be changed or are under no one's control. Specific to the context of price wars, firms are more likely to feel the pressure to retaliate to a competitor's price discount with a matching price in order to maintain their market share. Eventually, firms that are forced to cut their prices will lower the quality of their services and products to maintain their profits (Heil and Helsen 2001). Information about a retailer's competitive position can influence a consumer's perceptions of his or her controllability of a price discount event (Hunt, Kernan, and Mizerski 1983). Accordingly, we suggest that lowering prices due to competitive pressure might create a notion of increased uncontrollability over retailer's prices. Since many consumers are aware that during price wars the reactions and actions focus almost exclusively on the competitors instead of the consumers, and this pricing interplay may not be sustainable, the resulting price discounts may affect consumers in a negative way, leading to negative emotions such as hesitance and feelings of uncertainty (Heil and Helsen 2001).

Appreciation means acknowledging the value and meaning of something (e.g., event, person) and feeling a positive emotional connection to it (Adler 2002). Although there are several aspects of appreciation, we focus on gratitude and interpersonal aspects. These aspects refer to noticing and acknowledging a benefit that has been received and feeling thankful for the efforts and actions of an "other." Appreciation is a positive emotional reaction to a benefactor for something good that has been bestowed upon us, especially including feeling positively about being cared for (Adler 2002; Adler and Fagley 2005). Therefore, if a consumer knows that price reductions are under the retailers' control (e.g., passing on the manufacturer's discount to the consumers), the consumer may express gratitude and think that since the discount came at the retailer's own volition, similar discounts could be offered in the future without sacrificing product quality. For example, Honea and Dahl (2005) found that sales promotions under a retailer's control create a perception of its generosity and consumers' appreciation toward the retailer. Therefore, as an extension to Schindler's (1998) work, which does not include a hypothesis regarding the effect of controllability on consumers' affective responses, we propose:

Hypothesis 4: The more consumers attribute a price discount's cause to a controllable reason, the greater their levels of appreciation.

\section{Affective and Behavioral Consequences}

The sales promotion literature highlights the relationship between affective and behavioral consequences. For Folkes (1998), consumers who feel confident about the price they paid are more likely to brag and thus spread information about the purchase. Schindler's (1998) study confirms that the perceived discount could have ego-expressive consequences and that confident consumers are more likely to buy the product and inform others of the purchase. Furthermore, price discounts influence consumers' purchase intention and willingness to spread this information to others through positive feelings (e.g., happiness), which is a consequence of both acquisition and hedonic values that consumers derive from their shopping experience (Bagozzi, Gopinath, and Nyer 1999; Grewal et al. 1998). For Sherman, Schiffman, and Mathur (2001), in addition to cognitive factors, the positive emotional state of consumers may be an important determinant of buying behavior. Therefore, the current study argues that appreciation as a positive arousal may lead to an increase in consumers' willingness to buy and spread the information to other consumers. In other words, when consumers feel appreciative of a retailer's promotion, they may express their gratitude by buying a product in that store and telling others about their shopping experience. Rather than measuring affective responses as mediating variables, Schindler (1998) treats them as dependent variables in his study and does not measure the relationship between them and consumers' behavioral responses. Therefore, the next three hypotheses are extensions of his work:

Hypothesis 5: The affective state of happiness resulting from price discounts will positively influence consumers' (a) willingness to buy and (b) WOM communication.

Hypothesis $6:$ The affective state of appreciation resulting from price discounts will positively influence consumers' (a) willingness to buy and (b) WOM communication.

Hypothesis 7: The affective state of self-confidence resulting from price discounts will positively influence consumers' (a) willingness to buy and (b) WOM communication. 


\section{METHOD}

In this study, 200 undergraduate business students were drawn from a large public university in the Southwestern United States. The students participated in the experiment in exchange for course credit. Seventeen participants' responses were not included in the study because of severe missing data and nonattentive responses. Consequently, there were a total of 183 valid questionnaires with a minimum of 21 participants in each cell. In order to extend and generalize Schindler's work, both male and female participants are included in the current study. Of the 183 respondents in this study, 66 were females and 117 were males (in Schindler's study, there were 148 female participants). The ages of the current study's participants ranged from 18 to 56 years with a mean age of 21.6 years (standard deviation $[\mathrm{SD}]=3.4$ ). Ninety-four percent of the student sample was age 25 or younger.

Consistent with Schindler's (1998) work, a digital camera was chosen as the experimental stimuli for the current study because it is a search product and therefore easy to use for price verification and comparison with competitors' products. Furthermore, it is attractive and relevant to and popular with student participants. The current study employed a 2 (internal versus external locus) $\times 2$ (unstable versus stable price discounts) $\times 2$ (uncontrollable versus controllable price discounts) between-subjects design.

In attribution research, there are two research paradigms: one simulational and reactive and the other retrospective and operant (Weiner 1985). In the current research, we used the first approach: participants were asked to imagine themselves in a particular price discount situation and then report the intensity of their affective and behavioral reactions that they thought would be experienced in the stated situation. Therefore, each of the eight scenarios asked participants to envision themselves buying a digital camera. After presenting the manipulations, we asked the subjects to indicate their attributional reactions, level of positive emotions (i.e., happiness, self-confidence, and appreciation), and behavioral reactions (purchase intention and WOM). In order to control the effect of a price discount size, we fixed the percentage of the price discount in the scenarios and also included price sensitivity as a control variable.

Further, due to the common happiness context in all eight of the scenarios and the potential effects of priming and transfer of affect, we ran three tests to be sure that those factors do not inflate the correlational values and path coefficients in the model. First, Harmon's one-factor test shows that there is no general factor that accounts for most of the covariance among the latent constructs. Second, the marker variable assessment technique recommended by Lindell and Whitney (2001) shows that partialling out the effect of the marker variable (e.g., price sensitivity) did not change the significance of partial correlations among the constructs, and 95 percent sensitivity analysis also validated the result. Finally, a technique offered by Malhotra, Kim, and Patil (2006) that is a variant of the marker variable analysis was used to test the possible inflation factor. The results of these three tests reveal no differences in sign or significance levels. Collectively, the results of these three tests suggest that priming and transfer of affect do not pose a serious threat to the interpretation of the results from this study. Two sample scenarios are in Appendix A.

\section{Measures}

In extension research, measurement is a critical issue. This study used scales identical to or slightly adapted from those in Schindler's (1998) work, as well as scales from the behavioral-pricing literature (see Appendix B).

\section{Manipulation and Realism Checks}

Since each independent variable has two conditions, we employed $t$-tests for manipulation checks. There were significant differences between the internal locus and external locus groups $\left(\mathrm{M}_{\text {internal }}=2.59, \mathrm{M}_{\text {external }}=6.05\right.$, $t(1,158)=-26.85, p<0.001)$, stable and unstable discount groups $\left(\mathrm{M}_{\text {stable }}=2.42, \mathrm{M}_{\text {unstable }}=6.44, t(1,134)=-24.16\right.$, $p<0.001$ ), and controllable and uncontrollable discount groups $\left(\mathrm{M}_{\text {uncontrollable }}=0.96, \mathrm{M}_{\text {controllable }}=6.21 t(1,112)=-10.41\right.$, $p<0.001)$. To investigate the realism of our manipulations, we also included two realism check items at the end of the questionnaire: "I could imagine an actual retailer doing the things described in the price discount situation earlier," and "I believe that the described situation could happen in real life" $\left(\alpha=0.87, \mathrm{M}_{\text {composite score }}=5.17, \mathrm{SD}=1.72\right)$.

\section{Validity Assessment}

A confirmatory factor analysis was performed using LISREL 8.71 to assess the measurement properties for locus, stability, controllability, happiness, appreciation, selfconfidence, willingness to buy, WOM communication, and price sensitivity. Since the variables appreciation and selfconfidence have only one indicator, they are not included in the measurement model. The results indicate a good overall fit of the model $\left(\chi^{2}(209)=283.79, p<0.001\right.$; RMSEA [root mean square error of approximation] $=0.04$; NNFI [nonnormed fit index $]=0.98$; CFI [comparative fit index $]=0.98$ ) 
Table 2

Correlation Matrix

\begin{tabular}{|c|c|c|c|c|c|c|c|c|c|c|}
\hline & $\begin{array}{c}\mathrm{M} \\
(\mathrm{SD})\end{array}$ & LCS & STAB & CONT & WTB & WOM & HAPP & APP & SC & PS \\
\hline Locus (LCS) & $\begin{array}{c}4.6 \\
(1.9)\end{array}$ & 1 & & & & & & & & \\
\hline Stability (STAB) & $\begin{array}{c}4.5 \\
(2.3)\end{array}$ & -0.02 & 1 & & & & & & & \\
\hline Controllability (CONT) & $\begin{array}{c}5.3 \\
(1.8)\end{array}$ & 0.007 & 0.03 & 1 & & & & & & \\
\hline $\begin{array}{l}\text { Willingness to Buy } \\
\text { (WTB) }\end{array}$ & $\begin{array}{c}5.9 \\
(0.8)\end{array}$ & $-0.23^{* *}$ & -0.02 & -0.02 & 1 & & & & & \\
\hline $\begin{array}{l}\text { Word of Mouth } \\
\text { (WOM) }\end{array}$ & $\begin{array}{c}4.3 \\
(1.2)\end{array}$ & $-0.24^{* *}$ & $0.60^{* *}$ & -0.02 & 0.11 & 1 & & & & \\
\hline Happiness (HAPP) & $\begin{array}{c}5.2 \\
(1.4)\end{array}$ & $-0.70^{\star \star}$ & $0.17^{*}$ & -0.02 & $0.28^{* *}$ & $0.30^{* *}$ & 1 & & & \\
\hline Appreciation (APP) & $\begin{array}{c}4.9 \\
(1.4)\end{array}$ & -0.09 & 0.02 & $0.42^{* *}$ & 0.08 & 0.02 & 0.09 & 1 & & \\
\hline Self-Confidence (SC) & $\begin{array}{c}5.1 \\
(1.5)\end{array}$ & $-0.34^{\star \star}$ & 0.02 & -0.08 & $0.33^{* *}$ & 0.10 & $0.32 * *$ & 0.06 & 1 & \\
\hline Price Sensitivity (PS) & $\begin{array}{c}4.9 \\
(1.4)\end{array}$ & 0.09 & -0.06 & -0.10 & 0.08 & -0.03 & -0.04 & -0.06 & $0.15^{*}$ & 1 \\
\hline
\end{tabular}

as well as strong psychometric properties of the measures. Specifically, all of the standardized factor loadings are statistically significant at $p<0.001$, which indicates convergent validity. The factor scores ranged from 0.63 to 0.98 , with positive signs. Evidence of internal consistency stems from composite reliability (values ranging from 0.70 to 0.98 ), alpha scores (values ranging from 0.70 to 0.98 ), and average variance extracted (AVE; values ranging from 0.60 to 0.96 ). Because the square root of the AVE value for each construct is higher than the interconstruct correlations, adequate discriminant validity exists (Fornell and Larcker 1981). We also analyzed whether the three emotions of happiness, self-confidence, and appreciation are distinct from one another. The results show that they are distinct emotions $\left(\lambda_{\text {happiness-item } 1}=0.97, \phi_{\text {happiness-item } 1}=0.06 ; \lambda_{\text {happiness-item } 2}=0.95\right.$, $\phi_{\text {happiness-item } 2}=0.10 ; \lambda_{\text {appreciation-item } 1}=0.09, \phi_{\text {appreciation-item } 1}=0.99$; $\left.\lambda_{\text {self-confidence-item } 1}=0.33, \phi_{\text {self-confidence-item1 }}=0.89\right)$. Descriptive information and bivariate correlations are provided in Table 2.

\section{RESULTS AND DISCUSSION}

This research investigates the consumers' affective reactions through which consumers' causal attributions to price discounts may influence their behavioral responses. Following Bagozzi and Yi (1994), we used the distribution-free approach of PLS (partial least squares) structural equation modeling to analyze the experimental data. We used Smart PLS 2.3 for our statistical analysis. Table 3 summarizes the estimation results.

Supporting Schindler's (1998) primary hypothesis, our study found that consumers who believe that they receive the discount for internal reasons experience strong self-confidence (H1a: $\gamma=-0.35, t=4.80$ ) and happiness (H1b: $\gamma=-0.69, t=20.19$ ). Through H1a and H1b, the current study successfully replicates Schindler's primary hypothesis.

Regarding the link between stability and the feeling of happiness, our findings suggest that when consumers attribute a price discount to an unstable reason in general, they have a tendency to feel happier $(\gamma=0.15, t=3.02)$, supporting $\mathrm{H} 2$. With respect to $\mathrm{H} 3 \mathrm{a}$, the results show that when a consumer attributes a price discount to an internal reason, the attribution that the price discount's cause is also unstable has a greater effect on the consumer's selfconfidence $(\gamma=-0.15, t=1.75)$. However, with respect to $\mathrm{H} 3 \mathrm{~b}$, our findings reveal that the relationship has the opposite directionality and is significant. In other words, our results show that consumers feel happy when they attribute a price discount to an unstable and external cause $(\gamma=0.11$, $t=2.16$ ). The rationale for this conflicting result may have to do with the nature of the emotion. The emotion of hap- 
Table 3

Path Coefficients from PLS Analysis

\begin{tabular}{|c|c|c|c|}
\hline Structural Path & Estimate & $t$-Value & $R^{2}$ \\
\hline \multicolumn{4}{|l|}{ Effects on Consumers' Affective Responses } \\
\hline Locus $\rightarrow$ Happiness & $-0.69 * *$ & 20.19 & 0.52 \\
\hline Stability $\rightarrow$ Happiness & $0.15^{* *}$ & 3.02 & \\
\hline Locus $\times$ Stability $\rightarrow$ Happiness & $0.11^{* *}$ & 2.16 & \\
\hline Locus $\rightarrow$ Self-Confidence & $-0.35^{* *}$ & 4.80 & 0.14 \\
\hline Locus $\times$ Stability $\rightarrow$ Self-Confidence & $-0.15^{\star}$ & 1.75 & \\
\hline Controllability $\rightarrow$ Appreciation & $0.42 * *$ & 7.02 & 0.18 \\
\hline \multicolumn{4}{|l|}{ Effects on Consumers' Behavioral Responses } \\
\hline Happiness $\rightarrow$ Willingness to Buy & $0.19^{* *}$ & 2.75 & 0.19 \\
\hline Self-Confidence $\rightarrow$ Willingness to Buy & $0.25^{* *}$ & 3.36 & \\
\hline Appreciation $\rightarrow$ Willingness to Buy & 0.09 & 1.09 & \\
\hline Happiness $\rightarrow$ WOM & $0.30 * *$ & 3.92 & 0.11 \\
\hline Self-Confidence $\rightarrow$ Word of Mouth & 0.00 & 0.04 & \\
\hline Appreciation $\rightarrow$ Word of Mouth & 0.02 & 0.36 & \\
\hline
\end{tabular}

piness is not necessarily associated with a specific agent (e.g., self, other), it is more of a circumstance-caused emotion. Therefore, consumers may feel happy when they find a short-term price discount irrespective of the agent source of the cause of the discount. However, since self-confidence is more of a self-referent emotion, when the cause of the discount is perceived as internal, this emotion may have suppressed the feeling of happiness. Since happiness is a circumstance-caused emotion, it may be more apparent when consumers attribute the reason for the discount to an external cause (e.g., there is no other emotion that may suppress the feeling of happiness when the reason is perceived as external). With regard to $\mathrm{H} 4$, when consumers attribute a price discount to a reason that is controllable by the retailer, they are more likely to feel appreciative $(\gamma=0.42, t=7.02)$, supporting $\mathrm{H} 4$.

Regarding the relationships between affective dimensions and consumers' behavioral responses, our findings suggest that when consumers experience happiness in a price discount situation, they are more likely to be willing to buy (WTB) the product and share this experience with others $\left(\beta_{\mathrm{WTB}}=0.19, t=2.75 ; \beta_{\mathrm{WOM}}=0.30, t=3.92\right)$, supporting $\mathrm{H} 5 \mathrm{a}$ and $\mathrm{H} 5 \mathrm{~b}$. Whereas, the feeling of appreciation does not have an effect on either willingness to buy or WOM communication, rejecting H6a and $\mathrm{H} 6 \mathrm{~b}\left(\beta_{\mathrm{wTB}}=0.09\right.$, $t=1.09 ; \beta_{\text {WOM }}=0.02, t=0.36$ ). The rationale for this lack of impact of appreciation may be that although consumers feel appreciative of retailers' initiatives to reduce the price, this may not be a sufficient reason for them to take such actions. Finally, regarding H7a, our findings suggest that the link between self-confidence and willingness to buy is strongly supported, meaning that when consumers feel confident about obtaining a discount, they are more likely to buy the product. However, the relationship between self-confidence and WOM communication (H7b) is insignificant $\left(\beta_{\mathrm{wTB}}=0.25, t=3.36 ; \beta_{\mathrm{wOM}}=0.00, t=0.04\right.$ ). The rationale for this finding may be that feeling confident about obtaining a discount is more of an introverted and self-referent feeling. Consequently, perceiving responsibility for getting a discount as a personal victory, consumers may prefer to keep this experience to themselves.

\section{Mediation Analysis}

Extending Schindler's (1998) work, our proposed model includes several potential mediation effects. Specifically, this research proposes that (1) happiness mediates the relationship between locus and stability and WOM and willingness to buy; (2) appreciation mediates the relationship between controllability and WOM and willingness to buy; and (3) self-confidence mediates the relationship between locus and WOM and willingness to buy. In order to test the mediation effects, the product of coefficients strategy was employed (Preacher and Hayes 2008). This approach was preferred to Baron and Kenny's (1986) causal step approach because (1) it ignores both the estimate of the indirect effect and the effect's standard error, which hampers the direct investigation of statistical significance, and (2) testing the 
Table 4

Test of Mediation: Bootstrap Results for Indirect Effects

\begin{tabular}{|c|c|c|c|c|}
\hline Path & $\begin{array}{l}\text { Indirect } \\
\text { Effect }\end{array}$ & $\begin{array}{l}\text { Standard } \\
\text { Error }\end{array}$ & LL $95 \% \mathrm{Cl}$ & $\mathrm{HL} 95 \% \mathrm{Cl}$ \\
\hline Locus $\rightarrow$ Happiness $\rightarrow$ Willingness to Buy & $-0.07 * \star$ & 0.03 & -0.01 & -0.145 \\
\hline Locus $\rightarrow$ Confidence $\rightarrow$ Willingness to Buy & $-0.04^{* *}$ & 0.02 & -0.02 & -0.01 \\
\hline Locus $\rightarrow$ Happiness $\rightarrow$ Word of Mouth & $-0.11 * *$ & 0.04 & -0.19 & -0.04 \\
\hline Locus $\rightarrow$ Confidence $\rightarrow$ Word of Mouth & -0.006 & 0.017 & -0.04 & 0.03 \\
\hline Stability $\rightarrow$ Happiness $\rightarrow$ Willingness to Buy & $0.018 * *$ & 0.009 & 0.003 & 0.037 \\
\hline Stability $\rightarrow$ Happiness $\rightarrow$ Word of Mouth & $0.018 * *$ & 0.01 & 0.002 & 0.04 \\
\hline Controllability $\rightarrow$ Appreciation $\rightarrow$ Willingness to Buy & 0.02 & 0.02 & -0.01 & 0.06 \\
\hline Controllability $\rightarrow$ Appreciation $\rightarrow$ Word of Mouth & 0.012 & 0.023 & -0.03 & 0.06 \\
\hline
\end{tabular}

Notes: $\mathrm{LL}=$ lower level; $\mathrm{HL}=$ higher level; $\mathrm{CI}=$ confidence interval. Values are calculated through a bootstrapping routine with 183 cases and 1,000 samples. ${ }^{* *} p<0.05$.

null hypothesis that the indirect effect is equal to zero means one less hypothesis test, which eventually lessens the likelihood that a type II error would occur. Mediation analysis was conducted with the SAS macro (Preacher and Hayes 2008). The bootstrapped 95 percent confidence interval and the product coefficient approach with a standard error estimate were used to test the significance of indirect effects in the models. As can be seen in Table 4, happiness mediates the relationship between locus and stability and WOM and willingness to buy; appreciation does not mediate the relationship between controllability and WOM and willingness to buy; and finally, self-confidence mediates the relationship between locus and willingness to buy but does not mediate the relationship between locus and WOM.

\section{THEORETICAL AND MANAGERIAL IMPLICATIONS}

The current study extends Schindler's (1998) research on smart shopper feelings, which provides preliminary evidence that price discounts that are designed to evoke attributions of responsibility enhance the promotions' affective appeal and behavioral consequences. As part of our extension effort, the replication of Schindler's primary hypothesis finds full support. According to the results of our study, seeing oneself as responsible for getting a price discount triggers heightened affective responses. Specifically, consumers who perceive themselves as responsible for obtaining a discount have a tendency to feel happier and more self-confident than the consumers who attribute price discounts to external reasons. Therefore, price promotions that are designed to evoke attributions of responsibility with a specific emphasis on happiness and self-confidence could become critical to retailer strategies. One specific example is referral price discounts (e.g., Biyalogorsky, Gerstner, and Libai 2000). Customers who refer retailers' services to their friends get significant price discounts on their next purchase and may feel happy and confident about what they have accomplished.

In his study, Schindler found that the effect of internal locus on WOM communication is not statistically significant. However, in our extension efforts, treating affective responses as mediators rather than dependent variables reveals some interesting results. Consumers' perception of responsibility for obtaining a discount increases their willingness to buy that product and talk about the shopping experience only through the feeling of happiness, whereas self-confidence mediates only the relationship between internal locus and willingness to buy. This empirical evidence is consistent with the suggestion that consumers who are feeling smart about their shopping experiences transfer this feeling into positive emotions that eventually influence purchase intention and WOM communication. For example, delighted customers, who get significant discounts because of their referral to friends, not only feel happy but also eventually carry over this positive feeling for buying and talking about this positive experience to others.

Further, our results show that happiness explains most of the variance in WOM communication. Bagozzi, Gopinath, and Nyer (1999) state that coping with positive emotions (e.g., happiness) often involves sharing one's good fortune and positive experience with others. Similarly, self-confidence explains most of the variance in consumers' willingness to buy. Consistent with Schindler's (1998) findings, monetary gain and having won an implied game against the seller could serve as a token of a victory, which eventually leads to willingness to purchase the discounted product. Interestingly, in this study, the fact that happiness explains most of the variance in WOM communication and that self- 
confidence explains most of the variance in willingness to buy emphasizes the importance of the causal attribution of internal locus in price discount situations (e.g., internal locus is the only causal attribution that leads to both happiness and self-confidence). Briefly, among the three causal attributions to price discounts, internal locus (e.g., seeing oneself as responsible for getting the discount) is the most critical one explaining the behavioral aspect of price discounts. Therefore, consistent with Schindler's (1998) findings, retailers should design price promotions that combine both monetary and nonmonetary incentives. Furthermore, as noted earlier, retailers should design price promotions in a way that they evoke attributions of responsibility. One specific example is the use of QR (quick response) codes. Retailers can use QR codes to engage customers in instant in-store price promotions. Customers with smartphones can scan QR codes to get instant price reductions, and their active involvement can make them feel responsible for getting the price discount.

Another interesting finding from the current study is that consumers feel happier when they take advantage of a price discount caused by an unstable reason (e.g., temporary price cuts) rather than a fixed and stable reason (e.g., EDLP). Extending Schindler's (1998) work, this finding reinforces the findings that even though consumers find an EDLP strategy helpful, they still would like to visit multiple stores to get good deals because they want to have an adventurous and hedonistic shopping experience (Chandon, Wansink, and Laurent 2000). The mediation analysis shows that happiness completely mediates the relationships between unstable price discounts and WOM and purchase intention. This finding implies that it is not the temporary price discounts that lead to purchase intention and WOM communication, it is the feeling of happiness that is created by the adventurous and hedonistic shopping experience that increases consumers' intention to purchase and their WOM communication. In other words, retailers should design in-store promotion activities in ways that can provide adventurous experiences (e.g., in-store price promotion games). The interaction between internal locus and instability reinforces the previous finding. The finding suggests that retailers that design temporary price cuts in a way that consumers will attribute finding these discounts to themselves would increase retailers' sales. As the last component of the attributional theory, controllability has a positive effect on appreciation, meaning that consumers are more appreciative when they know that price discount activity is volitional and under the seller's control. Our findings, however, show that appreciation does not lead to either purchase intention or WOM communication. For example, Target frequently announces that the temporary price cuts are due to rollback prices (voluntarily passing on the manufacturers' discount on consumer prices). But during price wars, in order to survive the competition, many firms are forced to reduce the prices below their previously set price levels and retaliate against competitors' price cuts. However, this may result in consumer hesitance and uncertainty. For example, when Amazon.com announced that it reduced the prices of the previous Kindle models because of the new Kindle Fire, manufacturers of other e-book readers retaliated against Amazon.com's price cuts and drastically lowered their prices. But the sales results were in the favor of Amazon .com and drastically reduced prices did not attract more customers to other e-book readers. The mediation analysis results also confirm this finding that appreciation does not mediate the relationship between controllability and purchase intention and WOM. This finding suggests that although consumers positively evaluate controllable price discounts and appreciate being taken care of, it is not a sufficient reason for them to consider buying the discounted product and share this experience with others. Consistent with Schindler's (1998) study, our research argues that consumers' affective and behavioral responses to price discount activities will be robust to their price sensitivity. Therefore, price sensitivity is controlled (e.g., by fixing the discount rate to 25 percent in the scenarios and including price sensitivity as a control variable). Based on our results, price sensitivity does not explain much of the variance in willingness to buy $(\gamma=0.08, t=0.80)$ or WOM communication $(\gamma=0.02, t=0.17)$. Furthermore, as part of our effort to extend Schindler's study, we included gender as a control variable. Interestingly, the findings indicate that females are more likely to be willing to purchase the discounted product $(\gamma=-0.20, t=3.2)$. This finding is consistent with previous research that shows that women have more of a tendency to buy discounted products (Blackwell, Engel, and Miniard 2005). However, our results also show that gender does not have a significant effect on WOM communication $(\gamma=-0.12, t=1.55)$. This is consistent with research that shows that males and females act similarly regarding their WOM communication behavior (Wiedmann, Walsh, and Mitchell 2001).

\section{LIMITATIONS AND FUTURE RESEARCH}

Our study is not without limitations. The study was conducted in controlled experimental conditions where the retailer store brand and product brand names were elimi- 
nated by using hypothetical brand names. If store brand loyalty effects had been taken into account, the results might have been different. Therefore, future studies could include the store and brand loyalty constructs. In order to get more robust and generalizable findings, future research could use more than one product. As metrics of emotions, we utilized single-item appreciation and self-confidence measures. Using more than single-item measures for these constructs may provide more stable and concrete results.

\section{CONCLUSION}

The current study successfully extends Schindler's (1998) research. It fully supports his primary finding-the distinct phenomenon of smart shopper feelings. Furthermore, the current study, drawing from attributional theory, extends Schindler's work by testing new relationships and provides more practical implications regarding how to design price discount activities to increase sales. Briefly, the current study goes beyond the focal point of smart shopper feelings and investigates the more comprehensive causal attributional framework. As Berthon et al. (2002) noted, extension research can facilitate further theory development. The purpose of our research will be fulfilled if it acts as a catalyst that sparks further research with reference to smart shopper feelings in the area of causal attributions to price discounts and consumers' affective and behavioral responses.

\section{REFERENCES}

Adler, Mitchel G. (2002), “Conceptualizing and Measuring Appreciation: The Development of a Positive Psychology Construct," Ph.D. dissertation, Rutgers University, New Brunswick, NJ.

and Nancy S. Fagley (2005), "Individual Differences in Finding Value and Meaning as a Unique Predictor of Subjective Well-Being," Journal of Personality, 73 (1), 79-114.

Ailawadi, Kusum L., Donald R. Lehmann, and Scott A. Neslin (2001), "Market Response to a Major Policy Change in the Marketing Mix: Learning from Procter \& Gamble's Value Pricing Strategy," Journal of Marketing, 65 (1), 44-61.

Bagozzi, Richard P., and Youjae Yi (1994), "Advanced Topics in Structural Equation Modeling," in Advanced Methods of Marketing Research, Richard P. Bagozzi, ed., Cambridge, MA: Blackwell, 1-52.

— Mahesh Gopinath, and Prashanth U. Nyer (1999), "The Role of Emotions in Marketing," Journal of the Academy of Marketing Science, 27 (2), 184-206.

Balachander, Subramanian, Bikram Ghosh, and Stock Axel (2010), "Why Bundle Discounts Can Be a Profitable Alternative to Competing on Price Promotions," Marketing Science, 29 (4), 624-638.
Baron, Reuben M., and David A. Kenny (1986), "The ModeratorMediator Variable Distinction in Social Psychological Research," Journal of Personality and Social Psychology, 51 (6), 1173-1182.

Bearden, William O., David M. Hardesty, and Randall L. Rose (2001), "Consumer Self-Confidence: Refinements in Conceptualization and Measurement," Journal of Consumer Research, 29 (June), 121-134.

Beedie, Christopher, Peter Terry, and Andrew Lane (2005), "Distinctions Between Emotion and Mood," Cognition and Emotion, 19 (6), 847-878.

Berthon, Pierre, Leyland Pitt, Michael Ewing, and Christopher L. Carr (2002), "Potential Research Space in MIS: A Framework for Envisioning and Evaluating Research Replication, Extension, and Generation," Information Systems Research, 13 (4), 416-427.

Biyalogorsky, Eyal, Eitan Gerstner, and Barak Libai (2000), "Customer Referral Management: Optimal Reward Programs," Marketing Science, 20 (1), 82-95.

Blackwell, Roger D., Paul W. Miniard, and James F. Engel (2005), Consumer Behavior, 10th ed., Cincinnati, OH: South-Western College.

Chandon, Pierre, Brian Wansink, and Gilles Laurent (2000), “A Benefit Congruency Framework of Sales Promotion Effectiveness," Journal of Marketing, 64 (4), 65-81.

DelVecchio, Devon, David H. Henard, and Traci H. Freling (2006), "The Effect of Sales Promotion on Post-Promotion Brand Preference: A Meta-Analysis," Journal of Retailing, 82 (3), 203-213.

Doods, William B., Kent B. Monroe, and Dhruv Grewal (1991), "Effects of Price, Brand, and Store Information on Buyer's Product Evaluations," Journal of Marketing Research, 28 (3), 307-319.

Folkes, Valerie S. (1998), "Recent Attribution Research in Consumer Behavior: A Review and New Direction," Journal of Consumer Research, 14 (4), 548-565.

Fornell, Claes, and David F. Larcker (1981), "Evaluating Structural Equation Models with Unobservable Variables and Measurement Error," Journal of Marketing Research, 18 (3), 382-388.

Garretson, Judith A., and Scot Burton (2003), "Highly Coupon and Sale Prone Consumers: Benefits Beyond Price Saving," Journal of Advertising Research, 43 (2), 162-172.

Gartner|G2 (2004), "Both EDLP and Hi-Lo Retail Pricing Can Work If Executed Properly," Stamford, CT, June (available at http://efox.cox.smu.edu/mktg6211/both_edlp_and_hilo .pdf).

Grewal, Dhruv, R. Krishnan Krishnan, Julie Baker, and Norm Borin (1998), "The Effect of Store Name, Brand Name and Price Discounts on Consumers' Evaluations and Purchase Intentions," Journal of Retailing, 74 (3), 331-352.

Hartline, Michael D., and Keith C. Jones (1996), "Employee Performance Cues in a Hotel Service Environment: Influence on Perceived Service Quality, Value, and Word-of-Mouth Intention," Journal of Business Research, 35 (3), 205-217.

Heil, Oliver P., and Kristiaan Helsen (2001), "Toward an Understanding of Price Wars: Their Nature and How They Erupt," International Journal of Research in Marketing, 18 (1-2), 83-98.

Hirschman, Elizabeth C. (1984), "Experience Seeking: A Subjectivist Perspective of Consumption," Journal of Business Research, 12 (1), 115-136. 
Holbrook Morris B., Robert W. Chestnut, Terence A. Olivia, and Eric A. Greenleaf (1984), "Play as a Consumption Experience: The Roles of Emotions, Performance, and Personality in the Enjoyment of Games," Journal of Consumer Research, 11 (2), 728-739.

Honea, Heather, and Darren W. Dahl (2005), "The Promotion Affect Scale: Defining the Affective Dimensions of Promotions," Journal of Business Research, 58 (4), 543-551.

Hunt, James M., Jerome B. Kernan, and Richard W. Mizerski (1983), "Causal Inference in Consumer Response to Inequitable Exchange," in Advances in Consumer Research, vol. 10, Richard P. Bagozzi and Alice M. Tybout, eds., Ann Arbor, MI: Association for Consumer Research, 136-141.

Lazarus, Richard S. (1991), "Progress on a Cognitive-MotivationalRelational Theory of Emotion," American Psychologist, 46 (8), 819-834.

Lin, Chien-Huang, and Hung-Chou Lin (2009), "The Effect of Mood States on Variety-Seeking Behavior: The Moderating Role of Price Promotion," Social Behavior and Personality: An International Journal, 37 (10), 1307-1311.

Lindell, Michael K., and David J. Whitney (2001), “Accounting for Common Method Variance in Cross Sectional Research Design," Journal of Applied Psychology, 86 (1), 114-121.

Malhotra, Naresh K., Sung S. Kim, and Ashutosh Patil (2006), "Common Method Variance in IS Research: A Comparison of Alternative Approaches and a Reanalysis of Past Research," Management Science, 52 (12), 1865-1883.

Manning, Kenneth C., and David E. Sprott (2007), "Multiple Unit Price Promotions and Their Effects on Quantity Purchase Intentions," Journal of Retailing, 83 (4), 411-421.

Oatley, Keith, and Jennifer M. Jenkins (1992), "Human Emotions: Function and Dysfunction," Annual Review of Psychology, $43,55-85$.

Peine, Klaus, Mark Heitmann, and Andreas Herrmann (2009), "Getting a Feel for Price Affect: A Conceptual Framework and Empirical Investigation of Consumers' Emotional Responses to Price Information," Psychology \& Marketing, 26 (1), 39-66.
Preacher, Kristopher J., and Andrew F. Hayes (2008), “Asymptotic and Resampling Strategies for Assessing and Comparing Indirect Effects in Multiple Mediator Models," Behavior Research Methods, 40 (3), 879-891.

Roseman, Ira J. (1991), “Appraisal Determinants of Discrete Emotions," Cognition and Emotion, 5 (3), 161-200.

Russell, Dan (1982), "The Causal Dimension Scale: A Measure of How Individuals Perceive Causes," Journal of Personality and Social Psychology, 42 (6), 1137-1145.

Schindler, Robert M. (1998), “Consequences of Perceiving Oneself as Responsible for Obtaining a Discount: Evidence for Smart-Shopper Feelings," Journal of Consumer Psychology, 7 (4), 371-392.

Sherman, Elaine, Leon G. Schiffman, and Anil Mathur (2001), "The Influence of Gender on the New Age Elderly's Consumption Orientations," Psychology \& Marketing, 18 (10), 1073-1089.

Smith, Craig, Kelly N. Hayness, Richard S. Lazarus, and Lois K. Pope (1993), "In Search of the 'Hot' Cognitions: Attributions, Appraisals, and Their Relation to Emotion," Journal of Personality and Social Psychology, 65 (5), 916-929.

"2009 Promo Industry Trends Report" (2009), Chief Marketer, December 1 (available at www.chiefmarketer.com/ promotional-marketing/2009-promo-industry-trendsreport-01122009/).

Wagner, Tillmann, Thorsten Hennig-Thurau, and Thomas Rudolph (2009), "Does Customer Demotion Jeopardize Loyalty?" Journal of Marketing, 73 (3), 86-98.

Wakefield, Kirk L., and J. Jeffrey Inman (2003), "Situational Price Sensitivity: The Role of Consumption Occasion, Social Context, and Income," Journal of Retailing, 79 (4), 99-102.

Weiner, Bernard (1985), "An Attribution Theory of Achievement and Motivation," Psychological Review, 92 (4), 548-573.

Wiedmann, Klaus-Peter, Gianfranco Walsh, and Vincent-Wayne Mitchell (2001), "The Man Maven: An Agent for Diffusing Market Information," Journal of Marketing Communications, 7 (4), 195-212.

Wierzbicka, Anna (1992), "Defining Emotion Concepts," Cognitive Science, 16 (4), 539-581. 


\section{APPENDIX A \\ Sample Scenarios}

\section{Experimental Scenario for Internal Locus, Stability, and Controllability Conditions}

You are in the process of making arrangements to attend your best friend's wedding this summer. You are quite excited about the wedding and decide to look into buying a digital camera so that you can take pictures of the event and make your friend's happiest day memorable. Since your money is tight, you have decided that you will continuously search until you find a place that offers the best deal for the camera that you want. For weeks, you have continually searched the Internet, studied the ads in your local newspaper, and compared prices at various retail stores. You think that deals are bound to exist somewhere, and you are keen to find a deal. You have spent a lot of time searching. But you are very set on finding the best deal ever! Today, you are again out comparing prices at various stores across town. Finally, at the local retailer Power-Mart, you find one of the cameras you have been interested in at a substantial 25 percent price discount. You feel relieved to have found the camera at a reduced price at last and think that without such an elaborate search on your part you would not have found such an offer. A sign inside the store says that the price reduction offered by Power-Mart is permanent. The price is guaranteed not to increase for a long time. One of the store employees tells you that Power-Mart offers this price decrease as a special treat to its customers.

\section{Experimental Scenario for External Locus, Instability, and Uncontrollability Conditions}

You are in the process of making arrangements to attend your best friend's wedding this summer. You are quite excited about the wedding and decide to look into buying a digital camera so that you can take pictures of the event. The past few weeks have been extremely busy for you. Consequently, you did not search at all for a camera. Today, purely by coincidence, you walk by the retailer Power-Mart at a local strip mall and see one of the cameras you have been interested in at a substantial 25 percent price discount. A sign inside the store says that the price reduction offered by Power-Mart is temporary, for two days only. After tomorrow, the price reduction will no longer be offered. One of the store employees tells you that Power-Mart was forced to reduce the price of the camera because of high competition with other retailers. Power-Mart had no choice but to reduce the price. 


\section{APPENDIX B \\ Constructs and Items}

\begin{tabular}{|c|c|c|c|}
\hline & $\begin{array}{l}\text { Factor } \\
\text { Loadings }\end{array}$ & CR/AVE & Based on \\
\hline Locus (semantic scale from 1 to 7 ) & & $0.95 / 0.91$ & Russell (1982) \\
\hline \multicolumn{4}{|l|}{ The reason I obtained the price discount ... } \\
\hline $\begin{array}{l}\text {. . is something internal (e.g., myself)/external (e.g., } \\
\text { Power-Mart) }\end{array}$ & 0.95 & & \\
\hline ... reflects an aspect or attribute of me/of Power-Mart & 0.96 & & \\
\hline$\ldots$ is about my behavior/is about Power-Mart & 0.94 & & \\
\hline Stability (semantic scale from 1 to 7 ) & & $0.98 / 0.93$ & Russell (1982) \\
\hline \multicolumn{4}{|l|}{ This price reduction is ... } \\
\hline ... permanent/temporary & 0.97 & & \\
\hline ... not going to change/going to change & 0.97 & & \\
\hline . . . stable over time/unstable over time & 0.96 & & \\
\hline$\ldots$ valid in the long term/valid in the short term & 0.96 & & \\
\hline Controllability (semantic scale from 1 to 7 ) & & $0.95 / 0.90$ & Russell (1982) \\
\hline \multicolumn{4}{|l|}{ This price reduction } \\
\hline . . . was not controllable/controllable by Power-Mart & 0.95 & & \\
\hline $\begin{array}{l}\ldots \text { is something Power-Mart had no power over/had } \\
\text { power over }\end{array}$ & 0.96 & & \\
\hline $\begin{array}{l}\text {.. could not have been regulated/could have been } \\
\text { regulated by Power-Mart }\end{array}$ & 0.95 & & \\
\hline $\begin{array}{l}\text { Happiness (Likert scale: } 1 \text { = "highly disagree," } 7 \text { = "highly } \\
\text { agree") }\end{array}$ & & $0.96 / 0.96$ & Honea and Dahl (2005) \\
\hline Happy & 0.98 & & \\
\hline Pleased & 0.98 & & \\
\hline Willingness to Buy (Likert scale: 1 = "low," 7 = "high") & & $0.85 / 0.68$ & Doods, Monroe, and Grewal \\
\hline $\begin{array}{l}\text { The likelihood that I would purchase the camera would } \\
\text { be ... }\end{array}$ & 0.88 & & $(1991)$ \\
\hline My willingness to buy the camera would be ... & 0.87 & & \\
\hline $\begin{array}{l}\text { The certainty that I would plan to purchase the camera } \\
\text { is... }\end{array}$ & 0.82 & & \\
\hline $\begin{array}{l}\text { The likelihood that I would consider buying the camera } \\
\text { is ... }\end{array}$ & 0.72 & & \\
\hline $\begin{array}{l}\text { Word of Mouth (Likert scale: } 1 \text { = "highly disagree," } 7 \text { = "highly } \\
\text { agree") }\end{array}$ & & $0.88 / 0.73$ & Hartline and Jones (1996) \\
\hline I would tell a lot of people about this discount. . . & 0.76 & & \\
\hline $\begin{array}{l}\text { I would encourage my friends and relatives to take } \\
\text { advantage of this discount }\end{array}$ & 0.89 & & \\
\hline $\begin{array}{l}\text { I would suggest to my friends and relatives to benefit from } \\
\text { this discount }\end{array}$ & 0.90 & & \\
\hline $\begin{array}{l}\text { I would share my knowledge of this discount with other } \\
\text { people }\end{array}$ & 0.86 & & \\
\hline $\begin{array}{l}\text { Price Sensitivity (Likert scale: } 1 \text { = "highly disagree," } 7 \text { = "highly } \\
\text { agree") }\end{array}$ & & $0.70 / 0.60$ & Wakefield and Inman (2003) \\
\hline $\begin{array}{l}\text { I am generally willing to make extra effort to find a low } \\
\text { price for a camera }\end{array}$ & 0.63 & & \\
\hline $\begin{array}{l}\text { I will generally change what I had planned to buy in order } \\
\text { to take advantage of a lower price for a camera }\end{array}$ & 0.83 & & \\
\hline I am generally sensitive to differences in prices of a camera & 0.85 & & \\
\hline
\end{tabular}

Notes: CR = composite reliability; AVE = average variance extracted. 